
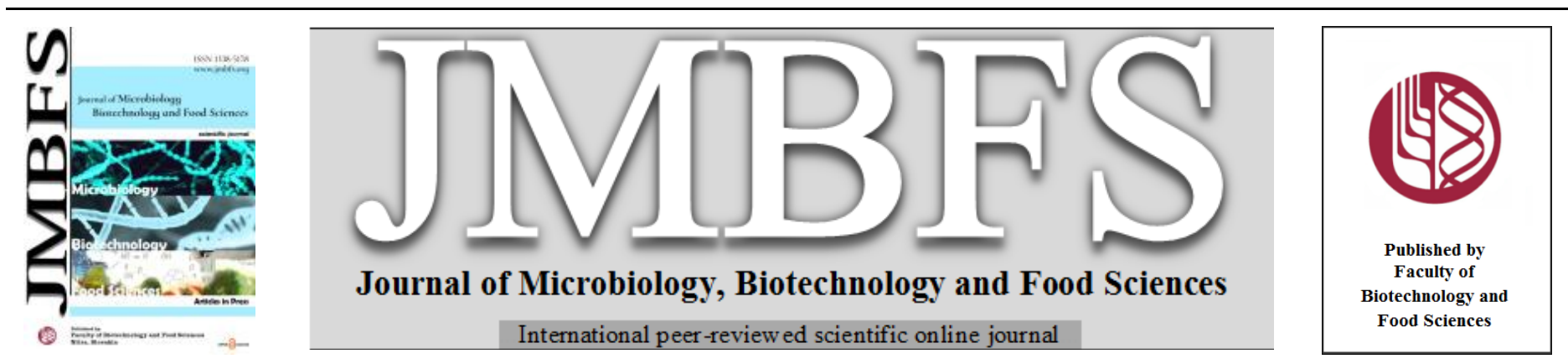

\title{
IN VITRO EFFECT OF NEWLY BACTERIOPHAGES ISOLATES AGAINST ESCHERICHIA COLI SEROGROUPS COLLECTED FROM THE LOCAL HOSPITAL LABORATORY; THEIR SPECIFIC CHARACTERIZATION AND IDENTIFICATION
}

\author{
Nidham M. Jamalludeen*l M.Sc., PhD, Dania M. Shakir ${ }^{2}$ M.B.Ch.B., F.I.C.M.S \\ Address(es): Dr. Nidham M. Jamalludeen, \\ ${ }^{1}$ University of Basrah, College of Medicine, Department of Microbiology, Basrah, Iraq, +964 7822839223. \\ ${ }^{2}$ University of Basrah, College of Medicine, Department of Microbiology, Basrah, Iraq.
}

*Corresponding author: njovc@yahoo.com

https://doi.org/10.55251/jmbfs.5478

\section{ARTICLE INFO}

Received 27. 10. 2021

Revised 21. 1. 2022

Accepted 26. 1. 2022

Published 1. 6. 2022

Regular article

open $\partial_{\text {ACCESS }}$

\section{ABSTRACT}

The aim of this study is to isolate a new bacteriophage with lytic effect against several serogroups of Escherichia coli that were isolated from different samples submitted to the local hospital laboratory. These serogroups are the main causative agents of bloodstream and urinary tract infections (UTIs) among Gram-negative bacteria. Three isolates of $E$. coli were used as a host to isolate phages from a hospital wastewater treatment plant. Eight phages were isolated and only three of them (EC-BSR1, EC-BSR2, and EC-BSR3) were considered for further characterization and identification. The three phages appear to belong to Myoviridae characterized by icosahedral heads, necks and contractile tails with tail fibers. Phage EC-BSR1 and EC-BSR2 had genome sizes of 67.06 and $68.04 \mathrm{~kb}$, respectively. All three phages were lysed $100 \%$ of E. coli serogroups that was tested in vitro and $42.7 \%, 61.7 \%$ and $44.7 \%$ in vitro lyses of ECOR collection reference. Phages were resistant to $\mathrm{pH}$ from 5 to 9, and phage EC-BSR3 appeared to be more resistant than the other two phages to an acidic and alkaline environment. These phages have the pattern of homologous DNA fragments after being digested with Acc1 and EcoR1 restriction enzymes. It was concluded that these phages are highly coli lytic for the E. coli serogroups isolates.

Keywords: Phages, E. coli, Basrah, In Vitro

\section{INTRODUCTION}

Escherichia coli (E. coli) is a bacterium that normally lives as a normal flora in the digestive system of humans and animals. They can be considered as equivalent populations in the gut and are a single causative agent of human pathogens. Consequently, it is the most common cause of urinary tract and blood stream infections between the gram-negative bacteria (Vila et al., 2016).

These bacteria possess various virulence factors such as toxins, adhesives, invasions, polysaccharide coats, and iron acquisition systems, which are not present in the commensal and gut pathogenic strains (Sannes et al., 2004). Shiga toxin-producing E. coli (STEC) is a species that can cause serious foodborne infections, primarily transmitted to humans through consumption of contaminated foods.

The genus Escherichia has many pathological patterns that cause a variety of diseases. Six different disease patterns have been reported causing intestinal diseases such as diarrhea or dysentery and other disease patterns causing extraintestinal infections, including UTI infections and meningitis (Vila et al., 2016).

Antibiotic resistance was observed during testing of E. coli serogroups and was observed at a high rate and a persistent increase. It is consistently higher for antimicrobial agents which is probably due to the extensive use of antibiotics in the poultry and veterinary industry (Allan et al., 1993; Angulo et al., 2004). As well as the use of antibiotics for long periods to treat human diseases such as using ampicillin. Over the course of two decades, the scientist has reported on resistance and also reported on the emergence and spread of multidrug-resistant bacteria, including strains that are resistant to newer antibiotics (Levy and Marshall, 2004). These and other concerns have led to a renewed interest in developing alternatives to antibiotics. One possible alternate is the use of virulent phages against serogroups of E. coli (Dissanayake et al., 2019).

It is assumed that phages of these serogroups are present with a frequency that allows us to isolate them. Phages are viruses that can attack bacteria and live and multiply alongside bacteria (Ackermann, 2000).

Phages can enter a single type or subtype of bacteria. This property, along with their ability to kill, makes them powerful antibacterial agents. Therefore, the objective of this project was to isolate virulent phages against Escherichia coli isolates and characterize them with respect to morphology, genome size and other potential characterization criteria.

\section{MATERIAL AND METHODS}

\section{Chemicals, Bacteria and Culture media}

Escherichia coli strains were isolated from several suspected samples submitted to the laboratory and all strains were provided by Dr.Bassam (laborator manager). Pathogenic strains were isolated from daily routine laboratory work at Al-Sadar Teaching Hospital (Department of Laboratory Diagnostics, Al-Sadar Teaching Hospital, Basrah, Iraq). Media and culture procedures were followed in the description obtained from the following references (Sambrook et al., 1989; Cappuccino and Sherman, 1992; Jamalludeen et al., 2007).

\section{Isolation of Bacteriophages and purification}

Phages were isolated from wastewater collected from the hospital treatment plant during the period from June to July 2020. The isolation protocol was carried out according to Jamalludeen $\boldsymbol{e t}$ al. ,(2007). LB broth was inoculated with a mixture of three different strains of Escherichia coli and incubated for $24 \mathrm{~h}$ at $37{ }^{\circ} \mathrm{C}$. The volume of wastewater was aseptically poured into a $1 \mathrm{~L}$ sterile flask and the further isolation procedure was performed according to the advice of Jamalludeen $\boldsymbol{e t}$ al. , (2007). The filtrate was then serially diluted $\left(10^{-1}\right.$ to $\left.10^{-9}\right)$ in SM buffer and a previously described protocol (Sambrook et al., 1989; Jamalludeen et al., 2007) was used to isolate a single plaque. Only three phages, called EC-BSR 1, EC-BSR 2 and EC-BSR 3 out of a total of 8 isolated phages, were considered for further characterization. These phages were propagated on one strain of Escherichia coli and the titer of each phage was determined by 10-fold dilution by the soft agar overlay method, and this procedure was repeated three times to obtain purified 
phages. Phage preparations were stored at $4{ }^{\circ} \mathrm{C}$. The phage suspension was purified using a $\mathrm{CsCl}$ gradient according to the protocol of Sambrook et al.. (1989).

\section{Electron Microscopy}

Three phages EC-BSR 1, EC-BSR 2, and EC-BSR3 were negatively stained and prepared for electron microscopy. A LEO $912 \mathrm{AB}$ power transmission filtered electron microscope operating at $100 \mathrm{kV}$ (Guelph Reginal STEM Facility, University of Guelph, Ontario, Canada) was used to capture phage images. All three phages were classified according to the guidelines of the Morphology (ICTV., 1995).

\section{Extraction of phage DNA}

DNA was extracted from the three phages (EC-BSR1, EC-BSR2, and EC-BSR3) according to the manufacturer's instructions using the kit provided by (Qiagen).

\section{Host range determination}

Escherichia coli isolates and the 72 strains comprising the E. coli reference group (ECOR) (Ochman and Selander, 1984) were used to test the lytic activity of the phage EC-BSR1, EC-BSR2, and EC-BSR3 according to the spot test procedure described by Sambrook et al. (1989).

\section{Resistance for the acid \& alkali environments}

A procedure described by Jamalludeen et al (2007) was used to test the ability of phages to survive at different $\mathrm{pHs}$. Phage suspensions were exposed to adjusted $\mathrm{pH}$ values 1 to 11 (using $\mathrm{NaOH}$ or $\mathrm{HCl}$ solution) over $16 \mathrm{~h}$ of incubation at $37{ }^{\circ} \mathrm{C}$, and then examined for viability.

\section{Pulsed-field gel electrophoresis}

Bacteriophages (EC-BSR1, EC-BSR2) were embedded in 1.0\% Seakem Gold agarose and electrophoresed with pulse times of $2.2-54.2 \mathrm{~s}$ pulses, at $6 \mathrm{~V} / \mathrm{cm}$ to determine the genome sizes of these two isolated phages. The full procedure has been described in detail by Jamalludeen et al., (2007). Phage EC-BSR3 was not performed in this experiment.

\section{Phages DNA digestion}

After restriction enzymes, AccI, EcoRI (New England Biolab, ON, Canada) was used to digest phage DNA by standard procedures (Sambrook $\boldsymbol{e}$ al., 1989). $3 \mu$ volumes of DNA were digested for $8 \mathrm{~h}$ at $37{ }^{\circ} \mathrm{C}$ and DNA was run by electrophoresis in a $1 \%(\mathrm{w} / \mathrm{v})$ agarose gel and stained with ethidium bromide to visualize the patterns of DNA fragments.

\section{RESULTS}

\section{Bacteriophage's isolation}

About eight phages were isolated by mixing three different isolates of Escherichia coli as host with a wastewater sample. Phages are given a name from only one to eight (EC-BSR1-EC-BSR 8). Phages EC-BSR1, EC-BSR2, and EC-BSR3 were selected for further characterization and investigation according to their morphological features described in figure 1 .

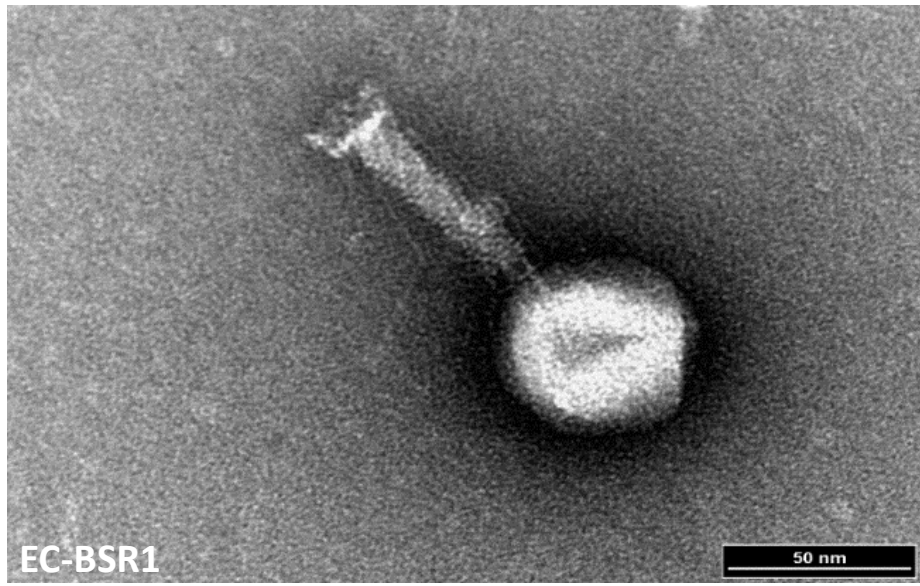

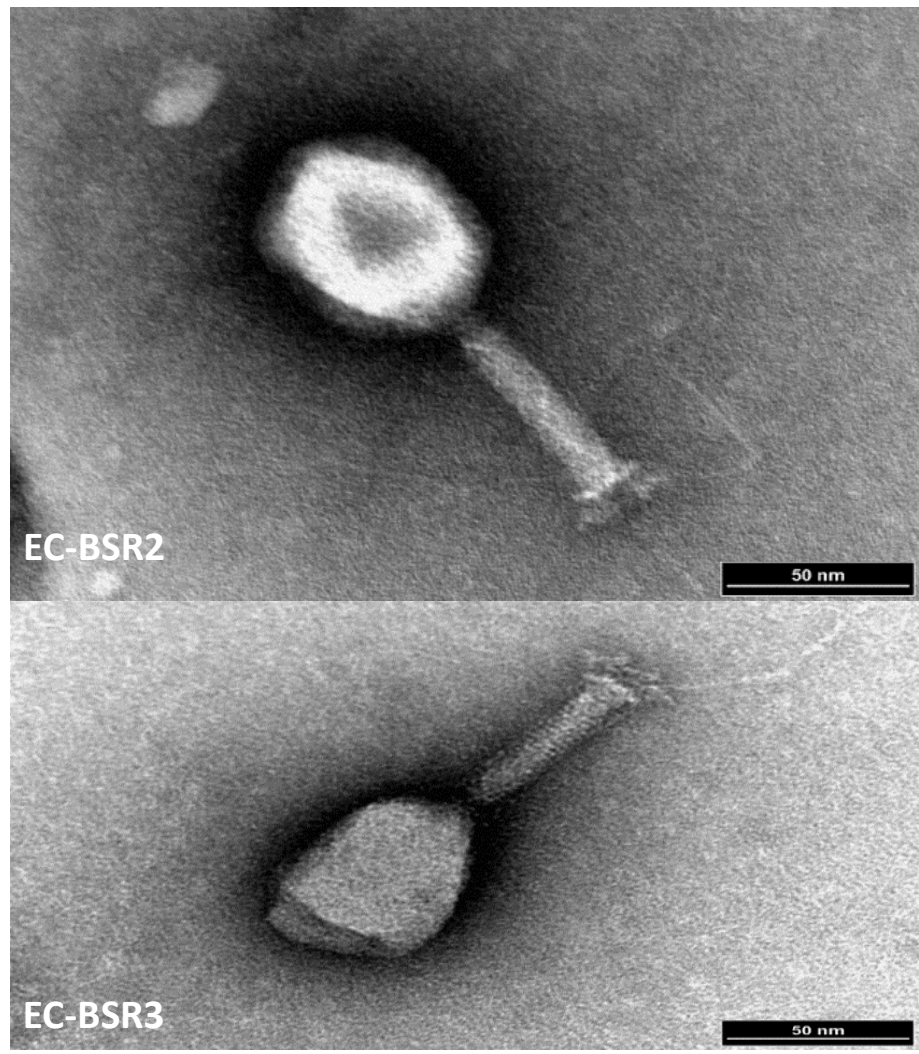

Figure 1 Electron microscope appearance of phages EC-BSR1, EC-BSR2 and ECBSR3. The phages have a neck and a contractile tail and icosahedral head. Bar = $50 \mathrm{~nm}$.

\section{Morphology and genome sizes (phages EC-BSR1, EC-BSR2, EC-BSR3)}

Images obtained from electron microscopy show that phages possess icosahedral heads, necks and contractile tails, with tail fibers as shown in figure 1 . These morphological features classify the family Myoviridae. To measure the head dimensions of EC-BSR1, EC-BSR2, and EC-BSR3 which were $65 \mathrm{~nm} \times 57 \mathrm{~nm}$, $72 \mathrm{~nm} \times 56 \mathrm{~nm}, 80 \mathrm{~nm} \times 56 \mathrm{~nm}$ and tail dimensions of $70 \mathrm{~nm} \times 16 \mathrm{~nm}, 69 \mathrm{~nm} \times 15$ $\mathrm{nm}$, and $70 \mathrm{~nm} \times 17 \mathrm{~nm}$ respectively (Tab 1). Six images were selected and measured and the mean values were recorded. Figure 2 and Table 1 showed that the whole genome of the phage EC-BSR1 and EC-BSR2 was an EC-BSR1 phage with a genome size of $67.06 \mathrm{~kb}$, and the phage size of EC-BSR2 was $68.04 \mathrm{~kb}$.

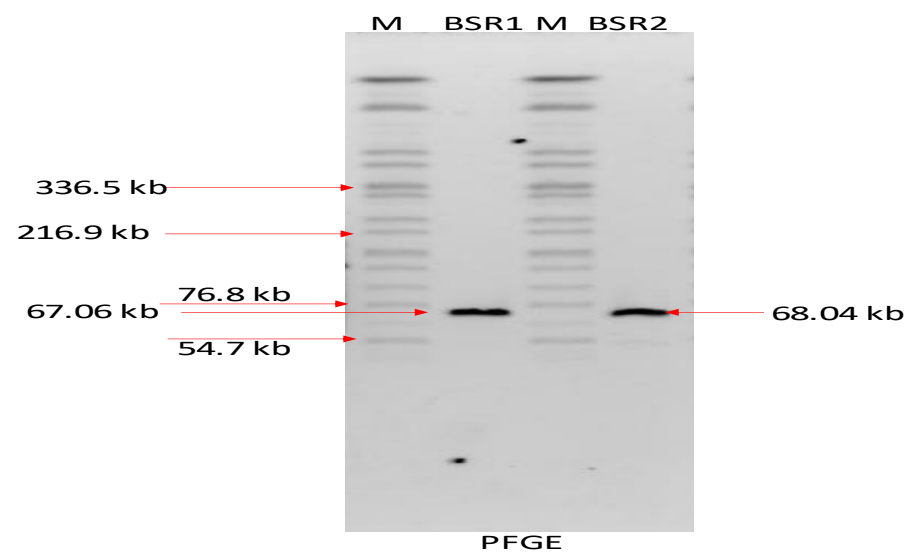

Figure 2 Pulsed-field gel electrophoretogram of phages EC-BSR1 and EC-BSR2 genome. $\mathrm{M}=$ Marker. EC-BSR3 was not done.

Table 1 Estimated dimensions and genome sizes of bacteriophages EC-BSR1, EC-BSR2, and EC-BSR3

\begin{tabular}{lcccccc}
\hline \multirow{2}{*}{ Phage } & $\begin{array}{c}\text { Genome } \\
\text { size }(\mathrm{kb})\end{array}$ & \multicolumn{2}{c}{$\begin{array}{c}\text { Head dimensions } \\
(\mathrm{nm})\end{array}$} & \multicolumn{2}{c}{ Tail dimensions } \\
& & Length & Width & Length & Width \\
EC-BSR1 & 67.06 & 65 & 57 & 70 & 16 \\
\cline { 3 - 7 } EC-BSR2 & 68.04 & 72 & 56 & 69 & 15 \\
EC-BSR3 & ND $^{*}$ & 80 & 56 & 70 & 17 \\
\hline
\end{tabular}

$\mathrm{ND}=$ Not done 


\section{Result of the Host range}

Table 2 , summarizes the results of phage lytic activity of EC-BSR1, EC-BSR2, and EC-BSR3. $100 \%$ of the $44 \mathrm{E}$. coli isolates supplied from the routine screening laboratory were killed with these phages and $42.7 \%, 61.7 \%$ and $44.7 \%$ of the 72 strains of the ECOR group, respectively.

Table 2 Summary of lytic activity of three phages against E. coli isolates and ECOR collection

\begin{tabular}{lccc}
\hline \multirow{2}{*}{ E. coli } & \multicolumn{3}{c}{ Phage activity (\% of isolates lysed) } \\
Isolates of daily routine & EC-BSR1 & EC-BSR2 & EC-BSR3 \\
\cline { 2 - 4 } ECOR collection (72) & 100 & 100 & 100 \\
\cline { 2 - 4 } & 42.7 & 61.7 & 44.7 \\
\hline
\end{tabular}

\section{pH Resistance}

The three phages were resistant to $\mathrm{pH}$ 5-9. Phage EC-BSR2 and EC-BSR3 were more resistant to acidic and alkaline environments than phage EC-BSR1 (Tab 3).

Table 3 Survival of phages EC-BSR1, EC-BSR2 and EC-BSR3 following exposure to $\mathrm{pH} \mathrm{1-11}$

\begin{tabular}{lccc}
\hline \multirow{2}{*}{$\mathrm{pH}$} & \multicolumn{3}{c}{ Titre of surviving, viable phages $(\mathrm{pfu} / \mathrm{mL})$} \\
1 and 2 & $\mathrm{ND}^{\mathrm{a}}$ & $\mathrm{EC}-\mathrm{BSR} 2$ & $\mathrm{EC}-\mathrm{BSR} 3$ \\
3 & $6.7 \times 10^{6}$ & $2.3 \times 10^{8}$ & $\mathrm{ND}$ \\
\cline { 2 - 4 } 4 & $1.3 \times 10^{7}$ & $5.5 \times 10^{8}$ & $6.5 \times 10^{8}$ \\
\cline { 2 - 4 } $5-9$ & $\geq 10^{8}$ & $\geq 10^{8}$ & $\geq 10^{8}$ \\
10 & $5.1 \times 10^{6}$ & $3.3 \times 10^{8}$ & $4.2 \times 10^{8}$ \\
\cline { 2 - 4 } 11 & $3 \times 10^{6}$ & $3.1 \times 10^{7}$ & $3.3 \times 10^{7}$ \\
\cline { 2 - 4 } control & $\geq 10^{8}$ & $\geq 10^{8}$ & $\geq 10^{8}$ \\
\hline
\end{tabular}

$\mathrm{a}=$ Not detected.

\section{Digestion patterns}

The phages EC-BSR1, EC-BSR2, and EC-BSR3 appear to be similar in the patterns of the fragments generated by their DNA digestion with AccI and EcoRI. The patterns of these enzymes are shown in figure 3 .

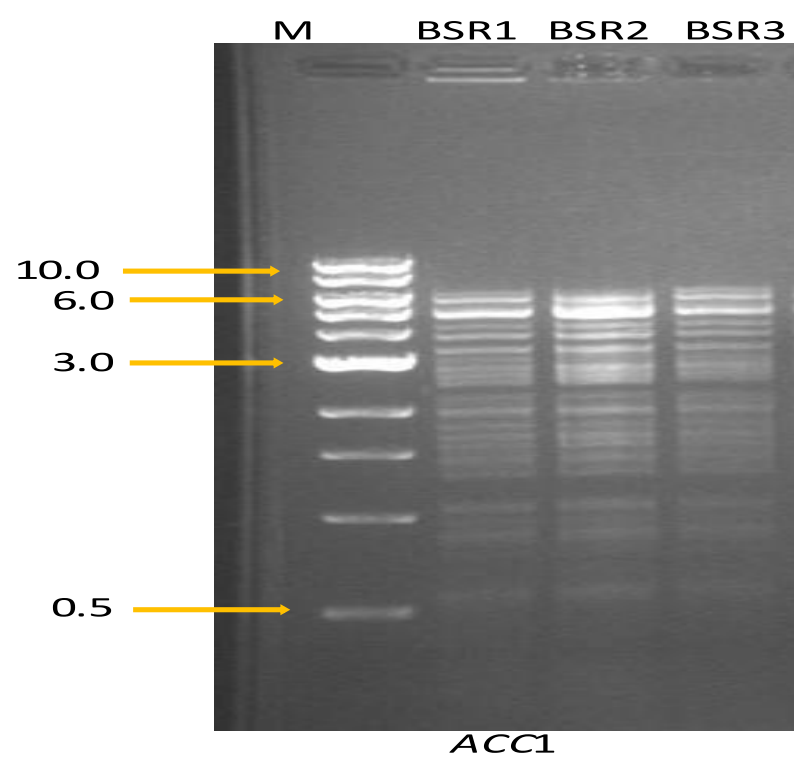

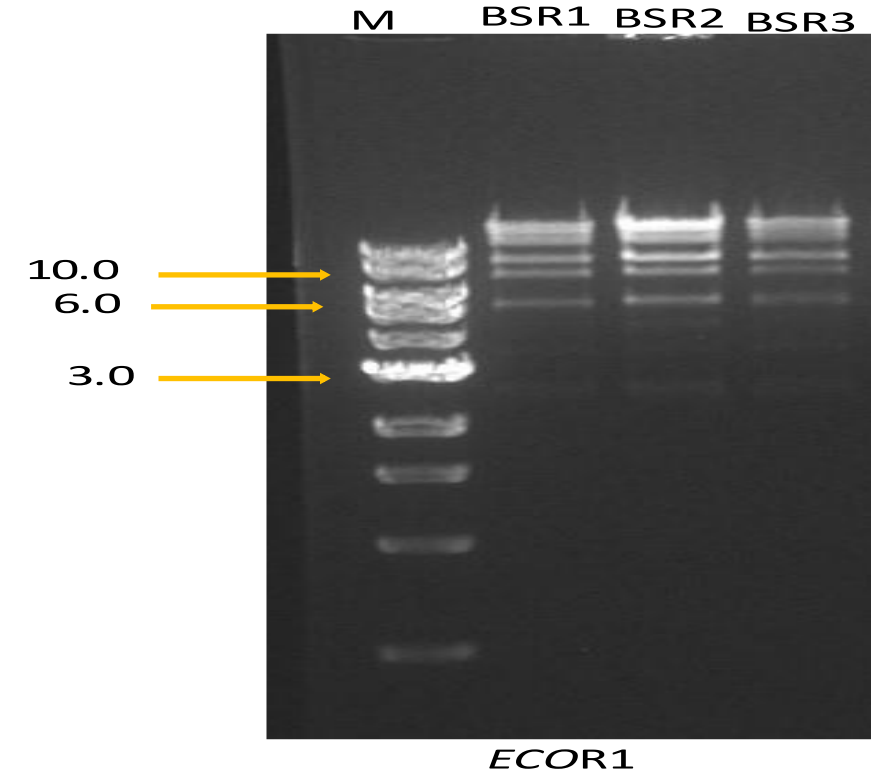

Figure 3 Electrophoresis on 1\% agarose of AccI and EcoRI restriction enzymes digest of phages EC-BSR1, EC-BSR2 and EC-BSR3 genome

\section{DISCUSSION}

Concerns have increased about the emergence of antibiotic resistance (Levy and Marshall., 2004; Kuehn, 2007). However, this study was planned to isolate and characterize a group of phages that were active against several strains of Escherichia coli isolates that could be used as an alternative to antibiotics. Phages EC-BSR1, EC-BSR2, and EC-BSR3 appeared active among the isolates isolated from routine work in the hospital laboratory. These phages were obtained from hospital wastewater treatment plants, where wastewater has always been the main sources of phage isolation. Huff et al. , (2002) also identified phages, designated SPRO2 and DAF6, which were only active against the $\mathrm{O} 2$ serotype of $E$. coli in chickens. Mohammed-Ali et al., (2015) and Jamalludeen., (2021) also isolated phages against the pathogenic Staphylococcus aureus which were considered good candidates for eradication of MRSA infection. From this study, phages were isolated against dominant strains of $E$. coli and targeted isolates from Basrah that have broad activity against $E$. coli isolates. According to the images of Phages ECBSR1, EC-BSR2, and EC-BSR3, it appears to be a member of the Myoviridae family by its morphology features and its contractile tails as shown in figure 1 . This family of phages is characterized by the presence of an icosahedral or elongated head with pronounced contractile tails that are somewhat rigid, thick in size and long (ICTV Report, 1995). Other classifications are the hallmarks of the Myoviridae taxonomy such as DNA structure, host ranges, base sequence similarity, protein composition and infection characteristics (Ackerman et al., 1992; Maniloff and Ackerman, 1998).

Phages were tested for their host ranges on $E$. coli isolates from the daily routine hospital laboratory, as well as their host range among $72 \mathrm{E}$. coli from the ECOR reference group, a widely used set of reference strains isolated between 1973 and 1983 from different geographical locations and many hosts. which represents the range of genetic variation in Escherichia coli (Ochman and Selander, 1984)

Phages in this study were susceptible to acidic environments at $\mathrm{pH} 1$ and 2 . While phages EC-BSR2 and EC-BSR3 appear to be more resistant to pH 3-11 than ECBSR1 (Tab 3). Hazem (2002) and Jamalludeen et al. (2007) report that phages are often very sensitive to protein denaturation in an acidic environment. However, these three phages were stable and live at $\mathrm{pH}$ values between 5 and 9. On the other hand, researchers reported in previous studies (Ackermann and DuBow, 1992; Jamalludeen et al., 2007) that most phages are able to survive longer $\mathrm{pH}$ range 59.

The patterns of DNA fragments obtained from digestion with $A c c \mathrm{I}$ and EcoRI restriction enzymes show identical patterns of phage DNA fragments. Based on these similarity patterns, they appear to be closely related and indicate a close genetic relationship figure 3 . Similar observations have been made by other researchers (Jamalludeen $\boldsymbol{e t}$ al., 2007). Whole genome sequences of these three phages can give a good idea of who these phages are and subtle differences can be indicated.

\section{CONCLUSION}

These three phages may play an important role as a candidate for phage therapy against Escherichia coli infection in vitro and/or in vivo. A mouse model was 
planned in in vivo evaluation experiments to test an individual and a cocktail group of these phages as a preventive and therapeutic effect (data not shown).

Acknowledgments: Most of this work was carried out in the Department of Microbiology, College of Medicine, University of Basrah, Iraq. Therefore, the authors are really grateful to the management staff for the kind support. The authors are also grateful to Bob Harris of the University of Guelph, Ontario, Canada for assistance with electron microscopy of phage images.

Conflicts of interest

There are no conflicts of interest.

\section{REFERENCES}

Ackermann, H-W. 2000. Bacteriophages. Encyclopedia of Microbiology. $2^{\text {nd }}$ ed

Vol 1 Academic Press. pp. 398-411.

Ackermann, H-W., DuBow, M. S., Jarvis, A. W., Jones, L. A., Krylov, V. N., Maniloff, J., Rocourt, J., Safferman, R. S., Schneider, J., Seldin, L., Sozzi, T., Stewart, P. R., Werquin, M., Wunsche, L. 1992. The species concept and its application to tailed phages. Arch. Virol. 124: 69-82 https://doi.org/10.1007/BF01314626

Allan, B. J., van den Hurk, J. V., and Potter, A. A. 1993. Characterization of Escherichia coli isolated from cases of avain colibacillosis. Can. J. Vet. Res. 57: 146-151.

Angulo, F. J., Nunnery, J. A., and Bair, H. D. 2004. Antimicrobial resistance in zoonotic enteric pathogens. Rev. Sci. Tech. 23: 485-496. https://doi.org/10.20506/rst.23.2.1499

Dissanayake U., Ukhanova M., Moye ZD., Sulakvelidze A., and Mai1 V. 2019. Bacteriophages Reduce Pathogenic Escherichia coli Counts in MiceWithout Distorting Gut Microbiota. Frontiers in Microbiology. Vol. 10 https://doi.org/10.3389/fmicb.2019.01984

Hazem, A. 2002. Effects of temperatures, pH-values, ultra-violet light, ethanol and chloroform on the growth of isolated thermophilic Bacillus phages. Microbiologica 25: 469-474.

Huff, W. E., Huff, G. R., Rath, N. C., Balog, J. M., Xie, H., Moore,Jr, P. A., and Donoghue, A. M. 2002. Prevention of Escherichia coli respiratory infection in broiler chickens with bacteriophage (SPR02). Poult. Sci. 81: 437-441. https://doi.org/10.1093/ps/81.4.437

International Committee on Taxonomy of Viruses (ICTV). 1995. Virus taxonomy, classification and nomenclature of virus. Sixth Report of the International Committee on Taxonomy of Viruses, Springer-Verlag/Wien, Austria. pp. 49-54

Jamalludeen NM,. 2021. Nasal Carriage of Staphylococcus aureus in Healthy Children and its Possible Bacteriophage Isolates in Basrah, Iraq. Biomed. \& Pharmacol. J, Vol. 14(1), 467-475. https://dx.doi.org/10.13005/bpj/2146

Jamalludeen, N., Johnson, R. P., Friendship, R., Kropinski, A. M., Lingohr, E. J., and Gyles, C. L. 2007. Isolation and characterization of nine bacteriophages that lyse O149 enterotoxigenic Escherichia coli. Vet. Microbiol. 124: 47-57. https://doi.org/10.1016/j.vetmic.2007.03.028

Kuehn, B. M. 2007. Antibiotic-Resistant "Superbugs" may be transmitted from animals to humans. JAMA. 298: 2125-2126. https://doi.org/10.1001/jama.298.18.2125

Levy SB, Marshall B. Antibacterial resistance worldwide: causes, challenges and responses. Nat Med 2004;10:S122-9. https://doi.org/10.1038/nm1145

Maniloff, J., Ackermann, H-W. 1998. Taxonomy of bacterial viruses: establishment of tailed virus genera and the order Caudovirales. Arch. Virol. 143 2051-2063.

Mohammed-Ali, MN and Jamalludeen, NM. 2015. Isolation and Characterization of Bacteriophage against Methicillin Resistant Staphylococcus aureus. J Med Microb Diagn 5:1. https://doi.org/10.4172/2161-0703.1000213

Ochman, H., Selander, R. K. 1984. Standard reference strains of Escherichia coli from natural populations. J. Bacteriol. 157: 690-693. https://doi.org/10.1128/jb.157.2.690-693.1984

Sannes MR, Kuskowski MA, Owens K et al. 2004.Virulence factor profiles and phylogenetic background of Escherichia coli isolates from veterans with bacteremia and 190:2121-8. https://doi.org/10.1086/425984

Sambrook, J., Fritsch, E.F., Maniatis, T., 1989. Molecular Cloning: A Laboratory Manual, second ed. Cold Spring Harbour Press, Cold Spring Harbour, NY.

Vila J., S'aez-L 'opez1, J., Johnson R., omling UR., Dobrindt U., Cant'on R., Giske CG., Naas T., Carattoli A., Mart'ınez-Medina M., Bosch J., Retamar P., Rodr'iguez-Ban J., Baquero F., and Soto1 SM. 2016. Escherichia coli: an old friend with new tidings FEMS Microbiology Reviews. Vol. 40, No. 4 https://doi.org/10.1093/femsre/fuw005 